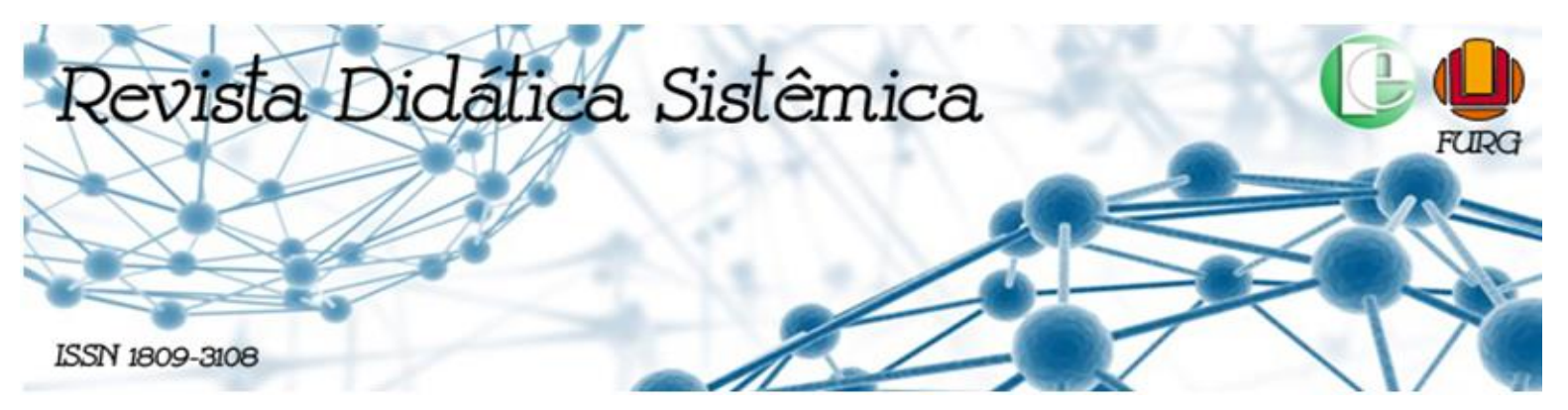

\title{
LETRAMENTO E LUDICIDADE: UM ESTUDO SOBRE AS PRÁTICAS QUE PRODUZEM APRENDIZAGENS SIGNIFICATIVAS E PRAZEROSAS NO PROCESSO DE AQUISIÇÃO DA LÍNGUA ESCRITA
}

Lucielle França de Lima ${ }^{1}$ Rochele da Silva Santaiana ${ }^{2}$ Veronice Camargo da Silva ${ }^{3}$

\section{RESUMO}

O presente artigo, oriundo de uma pesquisa de conclusão de curso, intentou compreender como as práticas lúdicas têm sido utilizadas nos processos de alfabetização e letramento. A alfabetização e o letramento fazem parte de uma fase importante no desenvolvimento infantil, que podem determinar a superação das demais fases acadêmicas, portanto, necessita ser estimuladora. Como discussão necessária à realização deste trabalho partiu-se da seguinte problematização: Como as práticas lúdicas têm sido utilizadas nos processos de alfabetização e letramento de crianças de duas turmas de primeiro ano, dos anos iniciais, em uma escola particular, do município de Alegrete? Este trabalho é uma pesquisa qualitativa, utilizando como abordagem a análise de dados e estudo de caso, com aplicação de um questionário com duas docentes que atuam em turmas de primeiro ano do Ensino Fundamental na referida escola. O presente estudo aponta serem fundamentais práticas pedagógicas permeadas por conhecimentos sobre as questões que discutem o letramento.

Palavras- chave: Práticas lúdicas. Letramento. Brincar.

\section{LITERACY AND LUDICITY: A STUDY ON PRACTICES THAT PRODUCE SIGNIFICANT AND PLEASANT LEARNING}

\footnotetext{
${ }^{1}$ Graduada em Pedagogia Licenciatura na Universidade Estadual do Rio Grande do Sul - UERGS, Brasil.

2 Doutorado em Programa de Pós-Graduação em Educação pela Universidade Federal do Rio Grande do Sul UFRGS, Brasil.

3 Professora adjunta e Professora do Mestrado Profissional em Educação da Universidade Estadual do Rio Grande do Sul - UERGS, Brasil.
} 


\begin{abstract}
This article, from a course conclusion research, attempted to understand how play practices have been used in literacy and literacy processes. Literacy and written code acquisition are part of an important phase in child development, which can determine the overcoming of other academic phases, and therefore needs to be stimulating. As a necessary discussion to the accomplishment of this work we started with the following problematization: How have the ludic practices been used in the written code acquisition and literacy processes of children of two first-year classes, of the initial years, in a private school, in the municipality of Alegrete? This work is a qualitative research, using as approach the data analysis and case study, with application of a questionnaire with two teachers who work in first year classes of Elementary School in said school. The present study points out that fundamental pedagogical practices are permeated by knowledge about the issues that discuss literacy.
\end{abstract}

Key- words: Play practices. Literacy. Play.

\title{
LETRAMIENTO Y LUDICIDAD: UN ESTUDIO SOBRE LAS PRÁCTICAS QUE PRODUCEN APRENDIZAJES SIGNIFICATIVOS Y PLACENTEROS EN EL PROCEDIMIENTO DE ADQUISICIÓN DE LA LENGUA ESCRITA
}

\section{RESUMEN}

Este trabajo proviene de una investigación realizada como una escrita final de conclusion de curso de graduación, el mismo busca comprender como las prácticas realizadas con ludicidad se han aplicado a los procesos de alfabetización y letramiento. La alfabetización y el letramiento son parte importante del desarrollo infantil, que pueden determinar las demás fases academicas y por lo que necesita ser estimuladora. La discusión en torno de la problemática central deste trabajo fue: Como las prácticas hechas con ludicidad pueden ser utilizadas en los procesos de alfabetización y letramiento de niños de dos clases de primer año, de la educación inicial de una escuela privada en la ciudad de Alegrete, Brazil? La misma, es una investigación de cuño cualitativo en el abordaje del Estudio de Caso donde se 
realize un análisis de datos cualitativos a partir de un cuestionario que fue aplicado a dos maestras de primer año de esa escuela. Este estudio mostró que las prácticas pedagogicas deben ser perpasadas por conocimientos teóricos en que se discute el letramiento.

Palabras centrales: ludicidad, letramiento, juegos pedagogicos.

\section{INTRODUÇÃO}

A concepção de infância sofreu diversas modificações ao longo da história do desenvolvimento social. No período que compreende a Antiguidade até a Idade Média, as crianças não eram citadas em registros históricos, uma vez que a conceituação de infância não existia enquanto etapa separada do grupo adulto para designar os mais novos, ou ainda, os que necessitassem de atenção e cuidados diferentes dos adultos. No século XIV começou-se a atribuir às crianças o papel de pequenos adultos, ou seja, eram vestidas, ensinadas e tratadas como tais. Somente do século XVII em diante é que surge "um sentimento de paparicação" (ARIÉS, 1981), em que a criança começa a ser diferenciada do adulto. A noção de infância emerge com a Modernidade passando por ela todos os sujeitos, independente das formas como vivenciam o brincar.

Atrelada à noção da infância, é possível pensar que o brincar é um dos mecanismos precursores da aprendizagem para construir e reconstruir conhecimentos. Mecanismos que podem ser compreendidos como uma forma lúdica utilizada por crianças e docentes de conduzir e mediar o aprendizado. A ludicidade auxilia no prazer em aprender, além de desafiar o educador a buscar jogos, atividades e criar situações nas quais a criança possa vivenciar o que aprende através da interação direta e satisfatória com os outros. O período de domínio da técnica (alfabetização) e uso competente social (letramento) que os infantes se apropriam da leitura e da escrita nos anos iniciais demarca este período. A ludicidade na alfabetização, no entendimento deste trabalho, pode ser tomada como estímulo, criatividade e assimilação que possibilita ao aluno a inserção no mundo letrado. Partiu-se, então, do seguinte problema de pesquisa: como as práticas lúdicas têm sido utilizadas nos processos de alfabetização e letramento de crianças de duas turmas de primeiro ano, dos anos iniciais, em uma escola particular, do município de Alegrete? 
O objetivo é compreender como as práticas lúdicas têm sido desenvolvidas e discutidas nos processos de alfabetização e letramento por parte dos docentes de uma escola particular do município de Alegrete no primeiro ano dos anos iniciais, levando os educandos a construírem um aprendizado significativo (GARDNER,1994). Ao entender os programas governamentais e discutir metodologias associadas às práticas educativas pretende-se, também, associar o papel da alfabetização lúdica com o aprendizado significativo dos docentes do $1^{\circ}$ ano. Para isso, foram coletados dados através de questionário aberto que serão na sequência melhor descritos.

\section{O ENSINO FUNDAMENTAL DE NOVE ANOS}

Nesta seção propõe-se uma análise mais pontual de uma política educacional e de um programa federal. Tenciona-se uma discussão referente ao Ensino Fundamental de Nove Anos, tendo em vista que funcionou como campo de possibilidades a implantação do programa federal "Pacto Nacional pela Alfabetização na Idade Certa".

Para que programas e políticas venham a ser implementadas, no que se refere às melhorias na educação, muitas alterações e emendas foram realizadas ao longo de todos esses anos de regulamentação do ensino público. Considero importante retomar a Lei $\mathrm{n}^{\circ} 4.024$, de 20 de dezembro de 1961, da LDB, no governo do presidente João Goulart. A designação para Ensino Fundamental era "Grau Primário". Nesse grau a criança teria de quatro a seis anos para desenvolver as suas potencialidades. Caso alguma criança não ingressasse com esta idade no primário, seriam criadas classes especiais de acordo com o seu nível intelectual. Conforme determina o capítulo II da LDB:

Art. 26 O ensino primário será ministrado, no mínimo, em quatro séries anuais.

Parágrafo único: os sistemas de ensino poderão estender a sua duração em até seis anos, ampliando, nos dois últimos, os conhecimentos do aluno, iniciando-o em técnicas de artes aplicadas, adequadas ao sexo e a idade.

Art 27 O ensino primário é obrigatório a partir dos sete anos, e só será ministrado na língua nacional. Para os que iniciarem depois dessa idade, poderão ser formadas classes especiais, ou cursos supletivos correspondentes ao seu nível de desenvolvimento.

Este documento estabelece uma prática educativa compartimentada e excludente, pois leva em consideração o conhecimento do aluno apenas no momento em que ele necessita realizar uma prova para avançar a outra etapa de ensino. De acordo com a lei, subentender-se- 
ia que o aluno teria domínio dos conhecimentos anteriores desenvolvidos no grau primário, para poder "conhecer" e se "apropriar" de novos conhecimentos no Ginasial e no Colegial, formas como eram dividos os anos finais do Ensino Fundamental e o Ensino Médio respectivamente. Sem deixar de colocar em questão que aqueles que não ingressassem em idade adequada ao primário, seriam excluídos em classes ditas "especiais", pois se imaginava que eram pessoas não aptas ou com menos conhecimento do que aquelas que ingressaram aos sete anos de idade, conforme regulamentava a lei.

Essas ideias prevaleceram por dez anos, até entrar em vigor a lei $\mathrm{n}^{\circ} 5.692$, de 11 de agosto de 1971, da LDB, no governo do presidente Emílio Médici, que revogou os artigos 25, 26 e 27, citados anteriormente, na LDB de 1961 (SANTAIANA, 2008). Essa lei divide o ensino em dois níveis, visando à preparação dos educandos para o ingresso no mercado de trabalho. Entendia que as práticas pedagógicas deviam ser voltadas aos valores familiares, sociais e trabalhistas, padrões estabelecidos pela sociedade da época. Lei de princípios moralistas, impondo a preparação para uma sociedade doutrinada pelas normas das indústrias, com horários rígidos e disciplinadores. As escolas eram produtoras de mão de obra. Conforme o Capítulo I, do Ensino de $1^{\circ}$ e $2^{\circ}$ graus, previsto na LDB de 1961 ,

\footnotetext{
Art $1^{\circ} \mathrm{O}$ ensino de $1^{\circ}$ e $2^{\circ}$ graus tem por objetivo geral, proporcionar ao educando a formação necessária ao desenvolvimento de suas potencialidades como elemento de auto-realização, preparação para o trabalho e para o exercício consciente da cidadania.

Parágrafo $1^{\circ}$ Para efeito do que dispõem os artigos 176 e 178 da constituição, entende-se por ensino primário a educação correspondente ao ensino de $1^{\circ}$ grau, e por médio, o de $2^{\circ}$ grau.

\section{TÍTULO I DA EDUCAÇÃO}

Art $1^{\circ}$, parágrafo $2^{\circ} \mathrm{A}$ educação escolar deverá vincular-se ao mundo do trabalho e à prática social.

Até esse período pouco se modificou na educação. Constata-se que ainda tem aspectos capitalistas, doutrinadores e opressores. A lei de 1971 esteve em vigência até a instauração da Lei no 93.394, de 20 de dezembro de 1996.

A implementação do Ensino Fundamental de Nove Anos é uma ideia que emerge no cenário educacional no governo do Presidente Fernando Henrique Cardoso, com a Lei Federal 10.172, de 9 de janeiro de 2001, do Plano Nacional de Educação, que visava à ampliação do 
Ensino Fundamental para nove anos com ingresso de crianças aos seis anos de idade. (SANTAIANA, 2008).

Entretanto, essa discussão só teve andamento no governo do Presidente Luis Inácio Lula da Silva. Em fevereiro de 2004, o Ministério da Educação e Cultura (MEC) organizou um debate nacional, formando diversas assembleias em vários estados do Brasil para demonstrar o seu interesse em ampliar o Ensino Fundamental. A intenção era a de garantir melhores condições de alfabetização e letramento de crianças com o propósito de diminuir a evasão escolar e os índices de repetência (SANTAIANA, 2008). Foi apenas com o sancionamento da Lei $\mathrm{n}^{\circ} 11.114$, de 16 de maio de 2005 , que altera os artigos $6^{\circ}, 30^{\circ}, 32^{\circ}$ e $87^{\circ}$ da Lei no 9.394 de 20 de dezembro de 1996, a LDB, que o Ensino Fundamental de Nove Anos tornou-se obrigatório com ingresso aos seis anos de idade. Posteriormente, é sancionada a Lei $\mathrm{n}^{\mathrm{0}}$ 11.274, de 6 de fevereiro de 2006, que torna obrigatória a matrícula no Ensino Fundamental de Nove Anos, a partir dos seis anos de idade, estabelecendo o prazo até 2010 para que os Municípios e Estados implementassem a obrigatoriedade em suas redes de ensino.

Uma sociedade constituída por pessoas pobres, analfabetas e sem acesso aos padrões básicos sociais (saúde e educação) gera prejuízos no desenvolvimento do país e, para evitar esse tipo de risco, o Governo busca políticas públicas para atender as necessidades dos menos favorecidos (KLEIN, 2007). As políticas se instituem para evitar que recaia sobre a população malefícios que podem gerar mais danos ao Estado. Isso é o que Klein (2007), Hattge (2007) e Santaiana (2008) apontam como gerenciamento do risco social por meio de políticas educacionais.

Portanto, o Ensino Fundamental de Nove Anos vem ao encontro dessa necessidade de desenvolvimento social, oportunizando o acesso da criança à educação para que possa, futuramente, servir de mão de obra qualificada para o país. Nesse sentido, também emergiu o "Pacto Nacional pela Alfabetização na Idade Certa", uma das apostas do Governo para garantir que os alunos permaneçam na escola, sendo "uma forma de economia" (HATTGE, 2007, p. 40). Economia no sentido de prover os sujeitos desde sua infância com aquilo que pode, posteriormente, gerar prejuízos à sociedade no futuro, tais como: analfabetismo, evasão escolar ou, ainda, estar à margem do que a sociedade espera. 
No decorrer de todos esses anos até a nossa atual LDB, o Ensino Fundamental teve o artigo 32 revogado pela lei 11.274, de 2006, ao implementar o Ensino Fundamental de nove anos, com início aos seis anos de idade. Com isso, tantas outras modificações foram realizadas na área da educação, adequando-se ao momento social e ao tipo de cidadão que essa sociedade espera formar. Pode-se aferir que muitos são os investimentos do MEC com a produção de materiais pedagógicos de orientação as escolas para o Ensino Fundamental de Nove Anos,

\begin{abstract}
Ao analisar os materiais do MEC, principalmente o documento "Ensino Fundamental de Nove Anos, orientações para a inclusão da criança de 6 anos de idade: + 1 ano é fundamental", observei toda uma produção de saberes específicos. Esses saberes são produzidos para orientar o trabalho pedagógico e as atividades escolares para as crianças de 6 anos de idade. Na verdade, os temas a que se refere o documento são os títulos dos capítulos do documento de 139 páginas, que visa orientar os sistemas de ensino no que tange as questões particulares e singulares da infância, bem como dos processos de alfabetização, avaliação e metodologias, que consistem em propostas de atividades que podem ser desenvolvidas com crianças de seis anos de idade. (SANTAIANA, 2008, p. 70).
\end{abstract}

Com essa implementação foi preciso constituir a capacitação profissional de professores, compreendendo que necessitariam de adequação em seus métodos pedagógicos já que os conteúdos e as faixas etárias das antigas séries seriam adequados e modificados à nova forma de organização do ensino. Portanto, a LDB em seu Título VI, Dos Profissionais da Educação, incluiu pela Lei n ${ }^{\circ} 12.056$ de 2009 a promoção de formação de professores, art 62, parágrafo $1^{\mathrm{o}}$ A União, o Distrito Federal, os Estados e os Municípios, em regime de colaboração, deverão promover a formação inicial, a continuada e a capacitação dos profissionais de magistério.

Pensando dessa forma, o MEC criou o Pacto Nacional pela Alfabetização na Idade Certa, o PNAIC, que tem por objetivo capacitar os professores das séries iniciais, no período de alfabetização e letramento das crianças.

\title{
3 O PACTO NACIONAL PELA ALFABETIZaÇÃo NA IDADE CERTA: OBJETIVOS E MÉTODOS DO PROGRAMA
}

O Pacto Nacional pela Alfabetização na Idade Certa, PNAIC, de acordo com o Caderno de Apresentação criado pelo MEC em 2012, para o conhecimento do programa pelo professor alfabetizador, diz que o mesmo é um acordo formal entre o Governo Federal, 
estados e municípios, com o compromisso de alfabetizar as crianças até, no máximo, os oito anos de idade, no final do ciclo de alfabetização. (BRASIL, 2012).

Infelizmente no Brasil é comum encontrarmos crianças no quinto ano do Ensino Fundamental que ainda não conseguem realizar uma leitura com compreensão, tendo dificuldades em produzir textos coesos e objetivos ${ }^{4}$. Ao ingressar com seis anos no primeiro ano do ensino fundamental, conforme discutido anteriormente, espera-se que a criança conclua a sua alfabetização e letramento até o terceiro ano,

Por outro lado não basta dominar o Sistema de Escrita Alfabética, mas a criança deve desenvolver a habilidade de fazer uso desse sistema em diversas situações comunicativas. Assim, é importante que no planejamento didático possibilitemos a reflexão sobre conhecimentos do nosso sistema de escrita, situações de leitura autônoma dos estudantes e situações de leitura compartilhada em que os meninos e meninas possam criar estratégias de compreensão de textos, bem como situações em que sejam possibilitadas produções textuais de forma significativa. (BRASIL, 2012, p.7).

Portanto, o PNAIC tem como objetivo principal contribuir para a formação continuada e o aperfeiçoamento dos métodos dos professores alfabetizadores. Constitui-se por um conjunto de ações, materiais e referências curriculares e pedagógicas, ofertados pelo MEC, apoiando-se em quatro eixos: formação continuada, materiais didáticos, avaliações sistemáticas e gestão

Para que essa formação continuada aconteça de forma significativa, existem equipes de trabalho para realizar diferentes tarefas objetivando a aprimoração das práticas de alfabetização e letramento. São divididas em duas instâncias: equipe central na Secretaria Municipal de Educação e equipes nas escolas. A equipe ligada a Secretaria deveria promover a formação das escolas.(BRASIL, 2012)

Já as equipes das escolas tem o dever de planejar o trabalho da escola, construir o Projeto Político Pedagógico, direcionando aos coordenadores pedagógicos tarefas de organizar e produzir documentos sobre a vida escolar da criança, articular ações entre a família e a escola (BRASIL, 2012, p.10),

Os professores também desempenham papéis fundamentais, senão o mais importante dentro deste programa, pois atuam diretamente em sala de aula com os alunos, desenvolvendo

\footnotetext{
4 Afirmação a partir da experiência de uma das pesquisadoras na condição de docente, e por ter contato com alunos de escolas públicas.
} 
conteúdos e habilidades que, juntamente com a equipe da escola, julgam importantes para a aquisição do código da escrita e da leitura em crianças. O professor deve ter clareza quanto aos seus objetivos, ao que e como ensina, e sobre qual concepção de alfabetização está direcionada a sua prática. Métodos a serem reproduzidos sem objetivos não são aceitos no PNAIC. (BRASIL, 2012).

De acordo com o PNAIC, o educador que se embasa teoricamente em suas práticas educativas, construindo um aprendizado sólido com seus alunos, tendo os objetivos de alfabetização e letramento bem definidos, terá sucesso em suas ações.

Levando em consideração o $4^{\circ}$ princípio do PNAIC, a ludicidade está inserida como uma prática intrínseca nos processos de alfabetização e letramento, assim como o cuidado e as relações sócio-afetivas entre professor e aluno. Ser lúdico nos anos iniciais é mais do que papel do professor, são condições para que se efetive a aprendizagem. Conforme Luckesi "o que caracteriza o lúdico é a experiência de plenitude que ele possibilita”(LUCKESI, 2000, p.2),

Esse programa, portanto, desenvolve ações que contribuam para os debates e práticas acerca dos processos de alfabetização e letramento, necessitando do trabalho efetivo e de qualidade de todos os envolvidos para que as crianças tenham garantido o seu direito de alfabetização e letramento, permitindo que façam parte da sociedade em que vivem, como seres atuantes e reflexivos. Cada criança possui um grande potencial para aprender, que as levam a internalizar os conhecimentos adquiridos, aproveitando assim, as oportunidades que lhe são oferecidas. (BITTENCOURT e FERREIRA, 2002).

\section{A LUDICIDADE COMO FORMA DE APRENDER BRINCANDO: ANÁLISE DOS QUESTIONÁRIOS}

Foram entrevistadas duas professoras alfabetizadoras que atuam numa Instituição de ensino privado, denominadas para o presente estudo como P1 para a professora 1 e P2 para a professora alfabetizadora 2.

A P1 é formada no Curso Normal em nível médio, em Licenciatura Pedagogia e possui duas especializações, uma em História Militar do Brasil e a outra em Ludopedagogia. Está trabalhando com alfabetização em anos iniciais há sete anos. A P2 é formada também no 
Curso Normal, antigo Magistério, e em Licenciatura Pedagogia, não possuindo ainda nenhuma especialização. Está trabalhando com alfabetização em anos iniciais há cinco anos.

Quando perguntadas sobre "Qual metodologia utilizas em sala de aula?" as professoras responderam que,

P1: Utilizo uma metodologia sociointeracionista- humanista.

P2: As aulas são bem dinâmicas, lúdicas, contextualizadas e significativas.

Nesse aspecto metodológico do questionário, a P1 demonstra ter maior compreensão de como realizar a sua prática docente, estando embasada em uma metodologia, citando o sociointeracionismo de Vygotsky, sendo também denominado socioconstrutivismo (ROMERO, 2015). Assim devemos relembrar que tal teoria entende que diferentemente do construtivismo o sujeito age diretamente com o objetivo e com o meio social (ROMERO, apud MAGALHÃES, 2007).

Apesar da P1 demonstrar compreender o que de fato é metodologia, a qual o professor deve seguir, não esclarece como desenvolve o seu trabalho, deixando pouco clara a sua resposta. De acordo com a citação acima, subentende-se que costuma trabalhar de maneira a valorizar o lúdico e o trabalho em cooperação cujo agente é a criança amparada numa teorização que considera importante. Já a P2 traz em sua resposta que "como metodologia" busca desenvolver aulas lúdicas, com significado, considerando o contexto. Nesta resposta pode-se analisar dois aspectos: a professora não demonstra ter conhecimento sobre o que é metodologia de ensino e, portanto, descreve as atividades que realiza em sala de aula como sendo contextualizadas, lúdicas, mas não esclarece por que ministra as suas aulas dessa forma.

Os dois pontos de vista, ao mesmo tempo em que partilham o entendimento, não esclarecem, em síntese, as posições, pois no que se refere à metodologia abordada, as respostas se confundem. Acreditam na ludicidade mas não explicitam os motivos. 
Nessa questão, ambas as professoras demonstram compreender, em síntese, o que é a ludicidade, pois quando a P2 traz a questão do aprender brincando, pode-se refletir que "a importância do brincar para o desenvolvimento infantil reside no fato de esta atividade contribuir para a mudança na relação da criança com os objetos”. (VYGOTSKY, 1994, p. 127)..

Quando as professoras foram questionadas sobre "Quais estratégias metodológicas lúdicas utilizas em sala de aula?" obtiveram-se as seguintes respostas:

P1: Como estratégias, prefiro atividades que envolvam os alunos.

P2: Desenvolver as atividades de forma dinâmica como: jogos, brincadeiras, contações de histórias, artes plásticas, e outros bem contextualizados com o tema de estudo.

Apenas a entrevistada P2 especificou quais as estratégias que utiliza em suas aulas e como torna esse aprendizado significativo. Exemplifica que suas atividades dinâmicas envolvem jogos, histórias e artes contextualizados com o tema de estudo, desenvolvendo suas estratégias metodológicas lúdicas com seus alunos.

Entende-se que esta professora valoriza a criação, a participação, a imaginação e o raciocínio dos educandos na realização de seus estudos. "Nesse sentido, a criança que puxar alguma coisa, torna-se cavalo, quer brincar com areia e torna-se padeiro, quer esconder-se, torna-se ladrão ou guarda” (BENJAMIN, 1984, p.76)

Através do desenvolvimento da imaginação, na capacidade de assumir papéis que não são seus, a criança descobre maneiras de se relacionar simbolicamente com o mundo, de enfrentar e resolver problemas, estando a par da cultura e da sociedade em que vive, desenvolvendo a criticidade, a lógica e o respeito pelo papel que o outro desempenha socialmente. Nesse sentido, é possível dizer que "o brinquedo pode funcionar como substituto dos objetos reais que fazem parte do seu cotidiano na vida em sociedade". (KLEIMAN, 2007, p.4).

Com isso, no momento em que a P1 coloca em sua resposta que desenvolve como estratégias metodológicas atividades que envolvam os alunos, muitas lacunas ficam "abertas", podendo diversas considerações serem feitas. O que para uns é considerado envolvente, para 
outros não. Por isso, essa resposta se tornou incompleta para o que a pesquisa objetiva, não por suspeitar que a professora não faça um trabalho lúdico. Longe disso, mas porque ficou difícil entender o que ela entende por estratégias, propostas de atividades lúdicas.

\subsection{DAS DECISÕES METODOLÓGICAS DAS ALFABETIZADORAS}

Essa seção abordará a análise das respostas do questionário referentes às práticas lúdicas em sala de aula.

No momento em que foram perguntadas "Considera-se um profissional que busca desenvolver os conteúdos de forma lúdica em suas aulas?” as professoras responderam:

P1: Sim, porque busco estratégias para que meus alunos consigam aprender e se superar.

P2: Sim, procuro atividades interessantes para trabalhar os conteúdos de forma contextualizada e interdisciplinar.

Aqui se percebe que as professoras se consideram profissionais em constante busca por estratégias que possibilitem o desenvolvimento lúdico dos conteúdos, porém continuam com respostas vagas, pois não relatam como e nem quais estratégias lúdicas buscam. É de fundamental importância que um alfabetizador, assim como qualquer outro professor, tenha clareza sobre os objetivos que quer alcançar, e como fazer para conseguir. As estratégias lúdicas precisam ser bem definidas e embasadas. Para que os alunos assimilem o aprendizado é necessário que exista a articulação entre a língua escrita, e oralidade e ludicidade mobilizando os alunos a participarem de situações práticas onde o "movimento será da prática social para o 'conteúdo' (procedimento, comportamento, conceito) a ser mobilizado para poder participar da situação, nunca o contrário, se o letramento do aluno for o objetivo estruturante do ensino". (KLEIMAN, 2007, p.6).

É preciso esclarecer mais uma vez que a ludicidade não é um fator excluído do processo de alfabetização e letramento, mas sim, primordial na priorização de uma alfabetização e letramento de qualidade, "de modo que a aprendizagem inicial da língua escrita exige múltiplas metodologias”. (SOARES, 2004, p.16). 
$\mathrm{Na}$ questão que procura saber "Utilizas jogos pedagógicos com os alunos? Como acontece a aprendizagem e o registro desses jogos?" as respostas também foram semelhantes,

P1: Costumo utilizar vários tipos de jogos que envolvam todas as áreas do conhecimento, bem como utilizo alguns jogos mais de uma vez, sempre colocando mais regras e exigindo um grau de complexidade maior. O registro inicial, normalmente é livre, em uma folha de ofício e registrado com materiais individuais do estojo. Em jogos de tabuleiro, por exemplo, costumo fazer uma ficha de registro do jogo, onde o aluno anota os dados dos participantes e quantifica as jogadas. Utilizo jogos como Nunca 10 (com material dourado), cuisinaire, bingos, jogos de memória e dominós.

P2: Sim, são vários jogos pedagógicos como: material dourado, blocos lógicos, formar palavras, memória, soma com dados e outros. A aprendizagem acontece naturalmente quando uma criança não consegue a outra ajuda e assim ocorre a reciprocidade dos conhecimentos.

Muitos dos jogos citados são desenvolvidos por ambas as alfabetizadoras e alguns, na área da matemática. A P2 utiliza os jogos como forma de desenvolver o raciocínio, a participação e troca de conhecimentos entre os alunos, considerando assim uma forma de integrar os conhecimentos e aprender com o outro.

O jogo tem um significado muito maior que apenas competir, ele desenvolve aptidões essenciais para a vida em sociedade. Assim, tanto a P1 quanto a P2 demonstram comprometimento e entendimento quanto à importância do jogo no crescimento intelectual dos alunos.

Contudo, o jogo fora do contexto da aula perde o seu sentido, pois assim como o brincar com o outro ou com objetos, sem contextualização e objetivos definidos, perdem o seu valor, conforme toda a discussão apresentada nessa pesquisa. As professoras em suas respostas mais uma vez não especificam quais os momentos em que aplicam esses jogos, como mediam o conhecimento entre as crianças através do jogo, apenas citando quais utilizam.

Por isso, reforça-se a importância de ter os objetivos e linhas metodológicas bem definidas, para que o professor não cometa equívocos com os seus alunos, sabendo o que e como aplicar, de forma a desenvolver objetivos. Dessa maneira, "a diferença entre ensinar 
uma prática e ensinar para que o aluno desenvolva individualmente uma competência ou habilidade não é mera questão terminológica”. (KLEIMAN, 2007, p.4).

Esse questionário mostrou o quanto ainda é necessário aos professores alfabetizadores discutirem sobre as dominarem as questões que permeiam o campo educacional em que atuam. Talvez por falta de esclarecimento, de formação continuada adequada e de qualidade ou, ainda, por falta de oportunidade de trocas de experiências com alfabetizadoras o que demanda interesse e envolvimento das escolas.. Acreditamos que as docentes procuram realizar ludicamente o trabalho mas talvez ainda não consigam explicitar em termos pedagógicos os motivos de suas escolhas metodológicas.

\section{CONCLUSÃO}

Mudanças ocorreram no cenário educacional ao longo dos anos como apontamos neste estudo, principalmente nas legislações. Tais mudanças geraram efeitos na formas como a alfabetização e o letramento possam ocorrer nas escolas.

Com a possibilidade de ampliação do Ensino Fundamental para Nove Anos sendo sancionada a lei no ano de 2005, visando a ampliação para 9 anos , objetivando diminuir a evasão escolar e os índices de repetência. Surge, portanto, a necessidade de criar projetos que auxiliem os educadores a desenvolverem o seu trabalho dentro dessas novas especificidades. O PACTO vem de modo a contribuir para a formação continuada dos profissionais da área, a fim de auxiliar na utilização dos métodos e na forma como ministrar os conteúdos de maneira mais lúdica e atrativa, pensando nos propósitos do Ensino Fundamental de Nove Anos, o EFNA.

O papel da ludicidade, todavia, se torna imensurável porque permite que o aluno construa as suas próprias relações de aprendizagem, de maneira natural, tendo o professor como mediador facilitador deste processo.

Conclui-se com este trabalho que a alfabetização e o letramento são processos que demandam de muito estudo, aperfeiçoamento e dedicação, acima de tudo, porque é uma fase fundamental na vida de todas as pessoas, que além de estarem decifrando o código da escrita, que embasa todo o nosso desenvolvimento social, estão interpretando as relações que 
constroem em seu dia a dia nas instituições em que participam, seja na família, na escola ou na rua, com os amigos.

\section{REFERÊNCIAS}

ÀRIES, Philippe. História Social da Criança e da Família. Tradução de Dora Flasksman.. Cidade: Guanabara, 1981.

BENJAMIN, W. Reflexões: a criança, o brinquedo e a educação. São Paulo: Summus, 1984.

BITTENCOURT, Glaucimar: FERREIRA, Mariana Denise Moura. A importância do lúdico na alfabetizaçãa. Trabalho de Conclusão de Pedagogia- Centro de Ciências Humanas e Educação da Universidade da Amazônia. Belém/Pará 2002. Disponível em: <http://www.nead.unama.br/bibliotecavirtual/monografias/IMPORTANCIA_LUDICO.p df > Acesso em: 4 ago 2016.

BRASIL. Secretaria de Educação Básica. Diretoria de Apoio à Gestão Educacional. Pacto nacional pela alfabetização na idade certa: formação do professor alfabetizador: caderno de apresentação/ Ministério da Educação, Secretaria de Educação Básica, Diretoria de Apoio à Gestão Educacional. Brasília: MEC, SEB, 2012. 40p.

BRASIL. Lei $\mathrm{n}^{\circ}$ 4.024 de 20 de dezembro de 1961. Lei de Diretrizes e Bases que divide o ensino em Grau Primário e Médio [...] Disponível em: <http://www2.camara.leg.br/legin/fed/lei/1960-1969/lei-4024-20-dezembro-1961353722publicacaooriginal-1-pl.html> Acesso em: 24 jun 2016.

BRASIL. Ministério da Educação. Lei de Diretrizes e Bases da Educação, no 7, de 14 de dezembro de 2010. Lei que fundamenta o Ensino Fundamental de Nove Anos [...]. Disponível em: <http://portal.mec.gov.br/dmdocuments/rceb007_10.pdf> Acesso em: 12 jul 2016.

BRASIL. Lei no 5.692 de 11 de agosto de 1971. Lei de Diretrizes e Bases da Educação que divide o Ensino em $1^{\circ}$ e $2^{\circ}$ graus [...] Disponível em:

<http://www2.camara.leg.br/legin/fed/lei/1970-1979/lei-5692-11-agosto-1971-

357752publicacaooriginal-1-pl.html> Acesso em: 24 jun 2016.

GARDNER, Howard. Estruturas da Mente: a teoria das inteligências múltiplas. Porto Alegre: Artes Médicas Sul, 1994. 
HATTGE, Morgana Domênica. Escola Campeã: estratégias de governamento e autoregulação. São Leopoldo: Unisinos, 2007. Dissertação (Mestrado em Educação) - Programa de Pós- Graduação em Educação, Universidade do Vale do Rio dos Sinos- Unisinos, São Leopoldo, 2007.

KLEIMAN, Angela B. Letramento e suas implicações para o ensino de língua materna. Santa Cruz do Sul: v. 32 n.53, p.1-25, dez, 2007.

KLEIN, Rejane Ramos. Voluntariado e os processo de in/ exclusão na escola. In. LOPES, Maura Corcini; DAL'IGNA, Maria Cláudia. In/ exclusão nas tramas escolares. Canoas: Ulbra, 2007.

LUCKESI, Cipriano Carlos. Ludopedagogia, Educação e Ludicidade. Ensaio GepelGrupo de Estudo e Pesquisa em Educação e Ludicidade. p. 57. Salvador: FACED/ UFBA, 2000 .

ROMERO, Priscila. Breve estudo sobre Lev Vygotsky e o Sociointeracionismo. Educação Pública, 2015. Disponível em: < http://educacaopublica.cederj.edu.br/revista/artigos/breveestudo-sobre-lev-vygotskye-o-sociointeracionismo> Acesso em: 12 out 2016.

SANTAIANA, Rochele da Silva. + 1 ano é fundamental: Práticas de Governamento dos Sujeitos Infantis nos Discursos do Ensino Fundamental de Nove Anos. Dissertação (mestrado)- Universidade Federal do Rio Grande do Sul. Faculdade de Educação. Programa de Pós- Graduação em Educação. Porto Alegre, 2008.

SOARES, Magda. Letramento e alfabetização: as muitas facetas. Poço de caldas: Revista Brasileira de Educação, 2004.

VYGOTSKY, L.S. A formação social da mente. São Paulo: Martins Fontes, 1994. 